\title{
Impact of Ultra-Sonication on Gelation Process in Dairy Products Incorporated with Polysaccharides
}

\author{
R. C. N. Thilakarathna*, G. D. M. P. Madhusankha \\ Department of Food Science and Technology, University of Sri Jayewardenepura, Gangodawila, Sri Lanka \\ Email: *chamodini@gmail.com, malinda.madhusankha@gmail.com
}

How to cite this paper: Thilakarathna, R.C.N. and Madhusankha, G.D.M.P. (2020) Impact of Ultra-Sonication on Gelation Process in Dairy Products Incorporated with Polysaccharides. Food and Nutrition Sciences, 11, 327-335.

https://doi.org/10.4236/fns.2020.115024

Received: March 30, 2020

Accepted: May 4, 2020

Published: May 7, 2020

Copyright $\odot 2020$ by author(s) and Scientific Research Publishing Inc. This work is licensed under the Creative Commons Attribution International License (CC BY 4.0).

http://creativecommons.org/licenses/by/4.0/

\begin{abstract}
Conventional or traditional methods for the use of food processing have been outperformed by novel approaches recently. One such promising technology is ultra-sonication and recent studies have shown better effects in physical characteristics of food which are induced by ultrasound. The previous researches further emphasize that the introduction of ultra-sonication on dairy proteins has resulted in the improvement of their structural, physical and chemical properties while it is widely used in hydrocolloid systems to accelerate the gelation process. Therefore this theory could be useful for the gelation of milk proteins in the presence of a polysaccharide. After discussing briefly on hydrocolloids and the theory of ultrasound, the possibility and the impact of ultrasound on gelation of milk protein mixtures with Carrageenan is highlighted in this study. The inherent characteristics of both milk proteins and carrageenan and properties of the ultrasound treatment have cumulatively effect on gelation. Therefore, there is a necessity to develop specific variables depending on the type of dairy product.
\end{abstract}

\section{Keywords}

Carrageenan, Gelation, Milk Protein, Polysaccharides, Ultrasound

\section{Introduction}

Hydrocolloids are thermo sensible polysaccharides incorporated in many dairy products as stabilizers and carrageenan is the most frequently consuming hydrocolloid. With the increasing competitiveness in dairy industry, a strong attention has been focused on emerging food technologies in order to uplift the quality of dairy products. Since the thermal treatment steps in the production process cause slight alterations in product quality, there is a trend to experiment 
non thermal alternative methods. Ultra-sonication has been identified as an effective non thermal treatment and research findings state that it facilitates the gelling process in milk proteins as well as in hydrocolloids. This technique can be identified as a timely necessity to research on and of the studies up to date, the beneficial impact of ultrasound was taken into account. As a new approach, the authors suggest the potential of introducing a polysaccharide in milk protein gelation. Therefore, this study is focused on the possible impact of ultra-sonication in milk protein and polysaccharide mixtures.

\section{Hydrocolloids}

Hydrocolloids are a group of long chain polymers comprising with fractions of polysaccharides which are used in a wide range of food applications; prominently as thickening and gelling agents [1]. The ability of hydrocolloids to induce the stabilization of physical properties and prevention of undesirable changes occur through moisture migration and gas cell coalescence are the promoting factors to use them extensively in food industry [2]. This effect is largely enhanced by the presence of a large number of hydroxyl $(-\mathrm{OH})$ groups which can increase their affinity to bind with water molecules, thus reducing the hydrophilic compounds. Therefore, hydrocolloids possess a high potential in altering the physical and organoleptic properties of food products while enhancing their quality. Recently, the use of hydrocolloids in food industry has been increased remarkably due to its ability to modify the rheology of food systems.

Commonly used types of hydrocolloids as thickeners are starch, guar gum, xanthum gum, locust bean gum, gum tragacanth, gum arabic etc. Hydrocolloids which give a gelling property are alginate, carrageenan, pectin, gelatin, gellan and agar. Among different hydrocolloids, the three types of carrageenan (kappa- $\kappa$, lambda- $\lambda$ and iota- $\iota$ ) play a dominant role in food applications, especially in dairy based systems. Carrageenan is structurally a linear sulphated galactan and it is extracted from marine red algae species [3]. The presence of half ester sulphate groups results in the chemical reactivity of carrageenan into a great extent and strong anionic fractions are formed as a result. In milk based products, carrageenan is incorporated as a stabilizer to enhance milk gel formation. In addition, it prevents ice crystal formation during the storage and retards the melting down process [4].

Depending on the sulphate group of the carrageenan, it reflects different types of gelling properties. For example, gels formed by t-carrageenan are soft and elastic while $\kappa$-carrageenan gives strong and brittle gels. Nevertheless $\lambda$-Carrageenan does not gel at all. The form of gel formation occurs from coil-to-helix transferring in $t$-carrageenan and respect to $\kappa$-carrageenan, formation of gel happens based on the double helices [5].

\section{Interactions between Carrageenan and Milk Protein}

The interactions between carrageenan and milk protein mixtures have been deeply experimented [6] and the interaction's effect on carrageenan gel forma- 
tion and rheological properties of the gel have been the key areas of researches throughout the past few decades [7].

Generally gelation occurs in two stages when cooling; firstly the helix formation and then aggregation [8]. This mechanism of gelation is largely influenced by the low concentration of carrageenan, ionic environment, $\mathrm{pH}$ and the temperature in the presence of milk proteins. It is apparent that carrageenan interacts precisely with casein and forms the complex with a three dimensional network [9].

Moreover, the impact of carrageenan in milk protein gelation is multifactorial, gelation behaviour of milk changes respect to $\kappa$-carrageenan and l-carrageenan corresponding to gel setting temperature, microstructure and melting profiles [10] where they have further revealed that increment in gel firmness by $\kappa$-carrageenan is higher than that of $\mathrm{t}$-carrageenan. Similarly, $\kappa$-carrageenan had shown a higher complex modulus in the linear viscoelastic region than $l$-carrageenan. Although the role of $\kappa$-carrageenan is prominent at its lower concentration, it is found that gelation is less at high concentration in the presence of milk proteins [9] more specifically it becomes important when $\kappa$-carrageenan concentration is $<0.018 \% \mathrm{w} / \mathrm{w}$. However, $\kappa$-carrageenan has the ability to adsorb into casein micelles and illustrates attractive characteristics at temperatures below Coli-helix transition temperature $\left(44^{\circ} \mathrm{C}\right)$ [11].

However, it is necessary to dissolve and disintegrate the solid matrix of carrageenan evenly throughout the milk based system for efficient functioning. Only $\lambda$-carrageenan is dissolved in cold water and a heat treatment should be done to disintegrate the kappa and iota forms. Therefore, the use of carrageenan in thermo sensible food products has been restricted. The strength of the gel formed by carrageenan increases with temperature and reaches a maximum at $110^{\circ} \mathrm{C}[12]$. However, if the milk products are heated above $60^{\circ} \mathrm{C}$, the nutritional compounds, flavour and aroma compounds are lost and milk proteins are denatured. Therefore, it is needed to follow an alternative method for heating to get the maximum outcome of carrageenan incorporated milk based products.

\section{Effect of Ultrasound Technology on Gelation}

Gelling of protein based dairy products has been a problem for a long time due to the heat treatment which contributes to the alteration of physical properties. Consequences of thermal treatments are prominent because of the destruction of vitamins, minerals and many nutritional factors with the denaturation of proteins and ultimately sensory characteristics will be affected negatively. Because of the unfavourable effects of heat treatment, it restricts the application of gelation on different types of dairy products, extent and time of providing heat and reduces the efficiency of the production [13].

Therefore, the advancement of emerging food technology has paved the way to focus on cold gelation methods. One such technique is ultra-sonication and ultrasonic wave is produced at frequencies above $16 \mathrm{kHz}$ which is a mechanical wave propagating by vibration of particles in the medium [14]. Research find- 
ings up to date have shown that ultrasound technique can be employed for processing applications such as homogenization, extraction, pasteurization etc. Basically, ultrasound application can be classified into low intensity (low power), a non-destructive way and high intensity (high power) which is considered as a disruptive method affecting chemical, mechanical and physical properties [15]. It is reported that low frequency ultrasound is appropriate to identify the changes of physical and chemical properties of food [14] by altering pressure, shear and temperature in a particular medium [16] while the latter is accounted to adjust acidity, firmness, sugar and ripeness.

The frequency range and the intensity of ultrasound waves are important parameters when deciding their appropriate usage in food industry. Based on the frequency range, ultra-sonication has been successfully used in some food applications. See Table 1.

Ultrasound application has been proven as an efficient way for the gelation of proteins as ultra-sonication produces protein conjugation and enhances the hydrolysis of protein enzymatically [21]. Power ultrasound processing has been successfully used for the gelation of $\boldsymbol{\kappa}$-carrageenan [22] and it is believed that ultrasound waves cause disruption of macro molecules to disintegrate them firmly. Ultrasound has a mixing power and depolymerisation of macro molecules take place due to physical and chemical effects accompanied by cavitation which is described as forming and collapsing of small bubbles in a liquid due to acoustic pressure fluctuation [23] [24].

The application of ultrasound assisted gelation on milk based systems has been experimented and it reveals that casein and whey protein show different responds towards ultra-sonication depending on their protein fraction and delivered energy density [25]. The study done by [26] shows that irrespective to the $\mathrm{pH}$ values, the gelling capacity of concentrates from whey proteins induced by ultrasound has become stronger, turned in reducing syneresis and observed differences in gel microstructure, when compared with non-treated samples from ultra-sonication. Further studies suggest that the application of ultrasounds in dairy industry improves the emulsification [13] and stabilisation [27] capacities.

Table 1. Properties of ultrasound in food application; data adapted from [17].

\begin{tabular}{|c|c|c|c|c|c|}
\hline \multirow{2}{*}{$\begin{array}{c}\text { Category } \\
\text { of ultrasound }\end{array}$} & \multicolumn{3}{|c|}{ Properties } & \multirow[b]{2}{*}{ Appropriate application } & \multirow[b]{2}{*}{ Reference } \\
\hline & Frequency range & Intensity & Effect of ultrasound & & \\
\hline $\begin{array}{l}\text { Low-frequency, high-power } \\
\text { ultrasound }\end{array}$ & $20-100 \mathrm{kHz}$ & Above $1 \mathrm{~W} / \mathrm{cm}^{2}$ & $\begin{array}{c}\text { Physical, chemical } \\
\text { \& biochemical effects } \\
\text { influenced by strong cavitation }\end{array}$ & $\begin{array}{l}\text { Emulsification } \\
\text { \& homogenization }\end{array}$ & $\begin{array}{l}{[18]} \\
{[19]}\end{array}$ \\
\hline $\begin{array}{c}\text { High-frequency, low power } \\
\text { ultrasound }\end{array}$ & $1-10 \mathrm{MHz}$ & Below $1 \mathrm{~W} / \mathrm{cm}^{2}$ & Gentle physical effects & $\begin{array}{l}\text { Non-invasive analysis } \\
\text { Monitoring food materials } \\
\text { Separations of } \\
\text { multi-component mixtures }\end{array}$ & [20] \\
\hline
\end{tabular}


Therefore, there is a heavy potential of utilizing ultrasound as an emerging technology on polysaccharide-protein mixtures to enhance their techno functionalities. In addition, this particular technology can be used in innovative food product development focussing on polysaccharide—protein matrix.

\section{Potential Benefits of Introducing Ultrasound Gelation in Polysaccharide-Protein Mixtures}

Texture, aroma, flavour and taste are very important sensory parameters that decide upon consumer's purchasing decision. Therefore, the means of improving the physical characteristics of a product is very useful when targeting the customers. Formation of gels with the use of high intensity ultrasound in order to improve the rheology of whey proteins matrix has been attentively explored by many researchers [28] [29] [30].

According to the research findings, high-intensity ultrasound treatment has resulted in improving textural characteristics like reducing syneresis and water holding capacity [16] [31] [32].

The study conducted by [32] shows that the use of ultra-sonication paves the way to improve the structure of the gel matrix and scanning electron microscopic images had been observed as honeycomb structures. Images of thermo sonicated yoghurt samples had exhibited more spores compared to non-sonicated samples. See Figure 1.

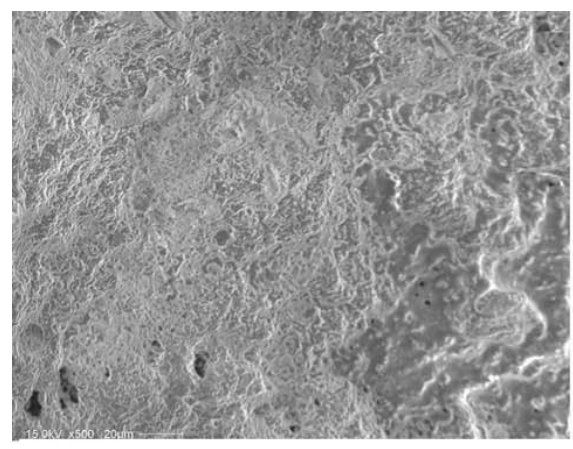

(A1)

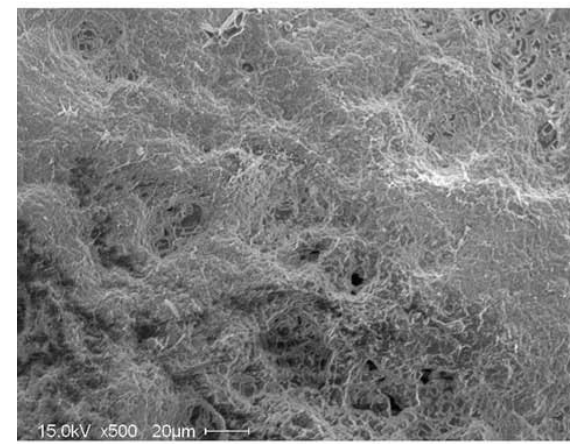

(B1)

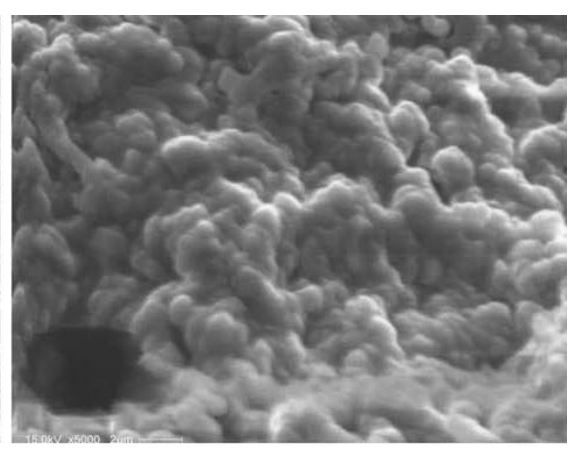

(A2)

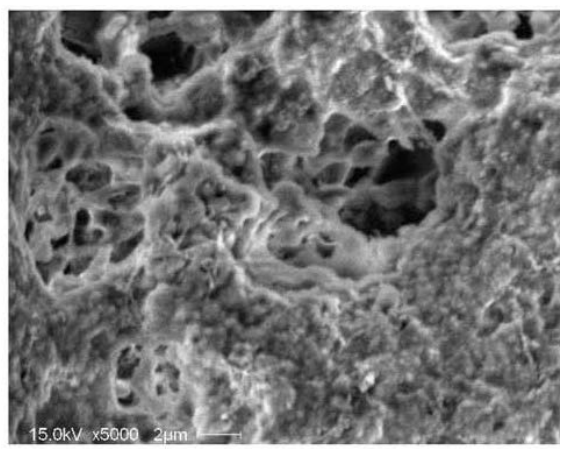

(B2)

Figure 1. Electron micrographs of yoghurts from conventionally (A) heated and (B) thermosonicated milk (1.5\% fat). (Magnification: A1, B1 ×500; A2, B2 × 5000); adapted from [32]. 
Acid gels prepared from sonicated casein solutions at $24 \mathrm{~Hz}$ and $130 \mathrm{~Hz}$ proves that ultrasound frequencies could lower the $\mathrm{pH}$ value of gelation point which resulted in enhancing the structure by reducing the size of the protein aggregates [33]. On the other hand, the use of heat and ultrasound under moderate pressure which is known to be thermo sonication was found to increase the gel strength of the yoghurt [34] and also the rheological properties of yoghurt gels [32] [35]. The fact that insufficient heat treatment causes in weakening the gel structure as whey proteins are not denatured in milk sufficiently, implies that alternative methods of using ultrasound with a polysaccharide could overcome these drawbacks.

Moreover, the sensory profile and volatiles of the ultrasound-induced yoghurts could improve because of the increment of relevant aldehydes, ketones, carboxylic acids and dimethylsulphide molecules [36]. Thus, it can be advantageous in using the technique of ultrasound in the process of milk protein mixtures. Nevertheless, there is proof of undesirable effects of ultrasound with high intensity due to the formation of compounds causing off odours and flavours which implies the necessity in identifying the most appropriate profile of ultrasound.

Further, the addition of polysaccharides like carrageenan could enhance the gelation of milk proteins as ultrasound causes to unfold the peptide chains within the milk proteins and encourage the bonding of polysaccharide-casein aggregates and whey protein-casein aggregates and subsequent bond formation of whey protein itself. The potential for enhancing the texture of milk protein mixture in such conditions is very promising. However, specific variables of ultrasound (amplitude, frequency respect to the concentration of carrageenan) for each type of product should be identified.

\section{Conclusion}

Ultra-sonication is a productive mechanism in industrial food applications related to gelation of polysaccharides incorporated with protein mixtures. Therefore it will be a smart solution for consequences due to high temperature treatments in food industry. However, to get the maximum output it is required to identify the unique variables of ultrasound specifically for each product.

\section{Conflicts of Interest}

The authors declare no conflicts of interest regarding the publication of this paper.

\section{References}

[1] Saha, D. and Bhattacharya, S. (2010) Hydrocolloids as Thickening and Gelling Agents in Food: A Critical Review. Journal of Food Science and Technology, 47, 587-597. https://doi.org/10.1007/s13197-010-0162-6

[2] Aliste, A.J., Vieira, F.F. and Del Mastro, N.L. (2000) Radiation Effects on Agar, Alginates and Carrageenan to Be Used as Food Additives. Radiation Physics and 
Chemistry, 57, 305-308. https://doi.org/10.1016/S0969-806X(99)00471-5

[3] Van de Velde, F. and de Ruiter, G.A. (2002) Carrageenan. In: Steinbuchel, A., DeBaets, S. and VanDamme, E.J., Eds., Biopolymers. Polysaccharides II: Polysaccharides from Eukaryotes, Wiley-VCH, Weinheim, Vol. 6, 245-274. https://doi.org/10.1002/3527600035.bpol6009

[4] Syrbe, A., Bauer, W.J. and Klostermeyer, H. (1998) Polymer Science Concepts in Dairy Systems: An Overview of Milk Protein and Food Hydrocolloid Interaction. International Dairy Journal, 8, 179-193. https://doi.org/10.1016/S0958-6946(98)00041-7

[5] Yuguchi, Y., Thuy, T.T.T., Urakawa, H. and Kajiwara, K. (2002) Structural Characteristics of Carrageenan Gels: Temperature and Concentration Dependence. Food Hydrocolloids, 16, 515-522. https://doi.org/10.1016/S0268-005X(01)00131-X

[6] Verbeken, D., Bael, K., Thas, O. and Dewettinck, K. (2006) Interactions between $\kappa$-Carrageenan, Milk Proteins and Modified Starch in Sterilized Dairy Desserts. International Dairy Journal, 16, 482-488. https://doi.org/10.1016/j.idairyj.2005.06.006

[7] Trckova, J., Stetina, J. and Kansky, J. (2004) Influence of Protein Concentration on Rheological Properties of Carrageenan Gels in Milk. International Dairy Journal, 14, 337-343. https://doi.org/10.1016/j.idairyj.2003.10.004

[8] Rees, D.A. (1972) British Food Manufacturing Industries Research. Symposium Proceedings, No. 13, London, 7-12.

[9] Drohan, D.D., Tziboula, A., McNulty, D. and Horne, D.S. (1997) Milk Protein-Carrageenan Interactions. Food Hydrocolloids, 11, 101-107. https://doi.org/10.1016/S0268-005X(97)80016-1

[10] Puvanenthiran, A., Goddard, S.J. and Augustin, M.A. (2002) Gelation of Mixed Gels Containing $\kappa$-Carrageenan and Skim Milk Components. Journal of Food Science, 67, 573-577. https://doi.org/10.1111/j.1365-2621.2002.tb10640.x

[11] Langendorff, V., Cuvelier, G., Michon, C., Launay, B., Parker, A. and de Kruif, C.G. (2000) Effects of Carrageenan Type on the Behaviour of Carrageenan/Milk Mixtures. Food Hydrocolloids, 14, 273-280. https://doi.org/10.1016/S0268-005X(99)00064-8

[12] Tziboula, A. and Horne, D.S. (2000) Effect of Heat Treatment on $\kappa$-Carrageenan Gelation in Milk. Gums and Stabilisers for the Food Industry, 10, 211-220. https://doi.org/10.1533/9781845698355.3.211

[13] Shanmugam, A. and Ashokkumar, M. (2014) Ultrasonic Preparation of Stable Flax Seed Oil Emulsions in Dairy Systems-Physicochemical Characterization. Food Hydrocolloids, 39, 151-162. https://doi.org/10.1016/j.foodhyd.2014.01.006

[14] Soria, A.C. and Villamiel, M. (2010) Effect of Ultrasound on the Technological Properties and Bioactivity of Food. Trends in Food Science and Technology, 21, 323-331. https://doi.org/10.1016/j.tifs.2010.04.003

[15] Tiwari, B.K. and Mason, T.J. (2012) Ultrasound Processing of Fluid Foods. In: Novel Thermal and Non-Thermal Technologies for Fluid Foods, Academic Press, Cambridge, 135-165. https://doi.org/10.1016/B978-0-12-381470-8.00006-2

[16] Dolatowski, Z.J., Stadnik, J. and Stasiak, D. (2007) Applications of Ultrasound in Food Technology. Acta Scientiarum Polonorum, Technologia Alimentaria, 6, 89-99.

[17] Chandrapala, J. and Leong, T. (2015) Ultrasonic Processing for Dairy Applications: Recent Advances. Food Engineering Reviews, 7, 143-158. https://doi.org/10.1007/s12393-014-9105-8

[18] Mason, T.J. and Luche, J.L. (1996) Ultrasound as a New Tool for Synthetic Chem- 
ists. In: Huhbard, C. and Eldik, R., Eds., Chemistry under Extreme or Non Classical Conditions, Wiley, New York, 317-380.

[19] McClements, D.J. (1995) Advances in the Application of Ultrasound in Food Analysis and Processing. Trends Food Science Technology, 6, 293-299.

https://doi.org/10.1016/S0924-2244(00)89139-6

[20] Leong, T., Johansson, L., Juliano, P., Mcarthur, S.L. and Manasseh, R. (2013) Ultrasonic Separation of Particulate Fluids in Small and Large Scale Systems: A Review. Industrial \& Engineering Chemistry Research, 52, 16555-1657. https://doi.org/10.1021/ie402295r

[21] Chen, L., Chen, J., Ren, J. and Zhao, M. (2011) Effects of Ultrasound Pretreatment on the Enzymatic Hydrolysis of Soy Protein Isolates and on the Emulsifying Properties of Hydrolysates. Journal of Agricultural and Food Chemistry, 59, 2600-2609. https://doi.org/10.1021/jf103771x

[22] Azizi, R. and Farahnaky, A. (2013) Ultrasound Assisted Cold Gelation of Kappa Carrageenan Dispersions. Carbohydrate Polymers, 95, 522-529. https://doi.org/10.1016/j.carbpol.2013.02.073

[23] Mason, T.J. and Cordmas, E.D. (1996) Ultrasonic Intensification of Chemical Processing and Related Operations. Transactions of the Institute of Chemical Engineers, 74, 511-516.

[24] Stephanis, C.G., Hatiris, J.G. and Mourmouras, D.E. (1997) The Process Mechanism of Erosion of Soluble Brittle Materials Caused by Cavitation. Ultrasonics Sonochemistry, 4, 269-271. https://doi.org/10.1016/S1350-4177(96)00040-5

[25] Silva, M., Zisu, B. and Chandrapala, J. (2018) Influence of Low-Frequency Ultrasound on the Physico-Chemical and Structural Characteristics of Milk Systems with Varying Casein to Whey Protein Ratios. Ultrasonics Sonochemistry, 49, 268-276. https://doi.org/10.1016/j.ultsonch.2018.08.015

[26] Zisu, B., Lee, J., Chandrapala, J., Bhaskaracharya, R., Palmer, M., Kentish, S. and Ashokkumar, M. (2011) Effect of Ultrasound on the Physical and Functional Properties of Reconstituted Whey Protein Powders. Journal of Dairy Research, 78, 226-232. https://doi.org/10.1017/S0022029911000070

[27] Bosiljkov, T., Tripalo, B., .Brnčić, M., Ježek, D., Karlović, S. and Jagušt, I. (2011) Influence of High Intensity Ultrasound with Different Probe Diameter on the Degree of Homogenization (Variance) and Physical Properties of Cow Milk. African Journal of Biotechnology, 10, 34-41.

[28] Kresic, G., Jambrak, V., Herceg, A.R. and Broncic S.R. (2008) Influence of Novel Food Processing Technologies on the Rheological and Thermo-Physical Properties of Whey Proteins. Journal of Food Engineering, 87, 64-73. https://doi.org/10.1016/j.jfoodeng.2007.10.024

[29] Ashokkumar, M., Lee, J., Zisu, B., Bhaskarcharya, R., Palmer, M. and Kentish, S. (2009) Sonication Increases the Heat Stability of Whey Proteins. Journal of Dairy Science, 92, 5353-5356. https://doi.org/10.3168/jds.2009-2561

[30] Jambrak, A.R., Mason, T.J., Lelas, V. and Kresic, G. (2010) Ultrasonic Effect on Physicochemical and Functional Properties of $\alpha$-Lactalbumin. LWT-Food Science Technology, 43, 254-262. https://doi.org/10.1016/j.lwt.2009.09.001

[31] Farahnaky, A., Zendeboodi, F., Azizi, R., Mesbahi, G. and Majzoobi, M. (2016) Solubilization of Bovine Gelatin Using Power Ultrasound: Gelation without Heating. Journal of Texture Studies, 48, 87-94. https://doi.org/10.1111/jtxs.12213

[32] Riener, J., Noci, F., Cronin, D.A., Morgan, D.J. and Lyng, J.G. (2009) The Effect of Thermosonication of Milk on Selected Physicochemical and Microstructural Prop- 
erties of Yoghurt Gels during Fermentation. Food Chemistry, 114, 905-911. https://doi.org/10.1016/j.foodchem.2008.10.037

[33] Madadlou, A., Emam-Djomeh, Z., Mousavi, M.E., Mohamadifar, M. and Ehsani, M. (2010) Acid Induced Gelation Behaviour of Sonicated Casein Solutions. Ultrasonics Sonochemistry, 17, 153-158. https://doi.org/10.1016/j.ultsonch.2009.06.009

[34] Vercet, A., Oria, R., Marquina, P., Crelier, S. and Lopez-Buesa, P. (2002) Rheological Properties of Yoghurt Made with Milk Submitted to Manothermosonication. Journal of Agricultural and Food Chemistry 50, 6165-6171. https://doi.org/10.1021/jf0204654

[35] Riener, J., Noci, F., Cronin, D.A., Morgan, D.J. and Lyng, G. (2010) A Comparison of Selected Quality Characteristics of Yoghurts Prepared from Thermosonicated and Conventionally Heated Milks. Food Chemistry, 119, 1108-1110. https://doi.org/10.1016/j.foodchem.2009.08.025

[36] Sfakianakis, P. and Tzia, C. (2017) Flavour Profiling by Gas Chromatography-Mass Spectrometry and Sensory Analysis of Yoghurt Derived from Ultrasonicated and Homogenised Milk. International Dairy Journal, 75, 120-128.

https://doi.org/10.1016/j.idairyj.2017.08.003 